\title{
Disrupted Saccadic Corollary Discharge in Schizophrenia
}

\author{
@Katharine N. Thakkar, ${ }^{1,2}$ @Jeffrey D. Schall,, ${ }^{1,3,4}$ @Stephan Heckers, ${ }^{1,3,5,6}$ and @Sohee Park ${ }^{1,3,5}$ \\ ${ }^{1}$ Department of Psychology, Vanderbilt University, Nashville, Tennessee 37240, ${ }^{2}$ Department of Psychiatry, University Medical Center Utrecht, 3584 CX \\ Utrecht, The Netherlands, ${ }^{3}$ Center for Integrative Cognitive Neuroscience and ${ }^{4}$ Vanderbilt Vision Research Center, Vanderbilt University, Nashville, \\ Tennessee 37240, and Departments of ${ }^{5}$ Psychiatry and ${ }^{6}$ Radiology and Radiological Sciences, Vanderbilt University, Nashville, Tennessee 37232
}

Disruptions in corollary discharge (CD), motor signals that send information to sensory areas and allow for prediction of sensory states, are argued to underlie the perceived loss of agency in schizophrenia. Behavioral and neurophysiological evidence for CD in primates comes largely from the saccadic double-step task, which requires participants to make two visually triggered saccadic eye movements in brief succession. Healthy individuals use $\mathrm{CD}$ to anticipate the change in eye position resulting from the first saccade when preparing the second saccade. In the current study with human participants, schizophrenia patients and healthy controls of both sexes performed a modified double-step task. Most trials required a saccade to a single visual target (T1). On a subset of trials, a second target (T2) was flashed shortly following T1. Subjects were instructed to look directly at T2. Healthy individuals also use CD to make rapid, corrective responses following erroneous saccades to $\mathrm{T} 1$. To assess $\mathrm{CD}$ in schizophrenia, we examined the following on error trials: (1) frequency and latency of corrective saccades, and (2) mislocalization of the corrective (second) saccade in the direction predicted by a failure to use CD to account for the first eye movement. Consistent with disrupted CD, patients made fewer and slower error corrections. Importantly, the corrective saccade vector angle was biased in a manner consistent with disrupted CD. These results provide novel and clear evidence for dysfunctional CD in the oculomotor system in patients with schizophrenia. Based on neurophysiology work, these disturbances might have their basis in medial thalamus dysfunction.

Key words: corollary discharge; double-step; efference copy; saccade; schizophrenia

Significance Statement

According to the World Health Organization, acute schizophrenia carries more disability weight than any other disease, but its etiology remains unknown. One promising theory of schizophrenia highlights alterations in a sense of self, in which self-generated thoughts or actions are attributed externally. Disruptions in corollary discharge (CD), motor signals sent to sensory areas that allow for the prediction of impending sensations, are proposed to underlie these symptoms. Direct physiological evidence, however, is limited. In nonhuman primates, inactivation of mediodorsal thalamic neurons disrupts CD associated with eye movements. Using the same task, we show similar impairments in schizophrenia patients, consistent with disrupted CD. These findings allow us to link clinical phenomenology to primate neurophysiology and interpret findings within a biological framework.

\section{Introduction}

Altered sense of self is a defining feature of schizophrenia (Sass and Parnas, 2003; Park and Nasrallah, 2014). Self-disturbances

\footnotetext{
Received Feb. 4, 2015; revised May 13, 2015; accepted June 1, 2015.

Author contributions: K.N.T., J.D.S., S.H., and S.P. designed research; K.N.T. performed research; K.N.T. analyzed data; K.N.T., J.D.S., S.H., and S.P. wrote the paper.

This work was supported in part by F31-MH085405-01 (K.N.T.), Netherlands Organization for Scientific Research Rubicon Grant (K.N.T.), NARSAD (S.P.), R01-MH073028 (S.P.), R01-MH70560 (S.H.), P30-HD015052 (S.P., J.D.S., K.N.T.), P30EY08126(J.D.S.), R01-MH055806 (J.D.S.), and the E.Bronson Ingram Chair in Neuroscience(J.D.S.). Wethank Lindsay Gilling McIntosh and Heathman Nichols for their assistance with clinical interviews and subject recruitment.

The authors declare no competing financial interests.

Correspondence should be addressed to either of the following: Dr Katharine Thakkar, Department of Psychiatry, University Medical Center Utrecht, Heidelberglaan 100, 3584 CX Utrecht, The Netherlands, E-mail: k.n.thakkar@umcutrecht.nl; or Dr Sohee Park, Wilson Hall 213, Department of Psychology, $11121^{\text {st }}$ Avenue South, Nashville, TN 37240, E-mail: sohee.park@vanderbilt.edu.

DOI:10.1523/JNEUROSCI.0473-15.2015

Copyright $\odot 2015$ the authors $\quad 0270-6474 / 15 / 359935-11 \$ 15.00 / 0$
}

manifest in, for example, delusions of being controlled by an outside force and anomalous source monitoring of internal speech resulting in auditory hallucinations (Frith, 1987). Such experiences have been hypothesized to be associated with abnormal corollary discharge (CD; Feinberg, 1978), the motor signals sent to sensory areas that allow for the prediction of future sensory states and the ability to distinguish self-generated from externally generated events (Wolpert and Ghahramani, 2000). Accordingly, disrupted CD could be one of the physiological underpinnings of the subjective loss of agency and self-other boundary in psychosis (Schneider, 1959).

Robust evidence for the central role of CD in internal monitoring and correction of movement plans has come from the saccadic double-step task in which two visual targets are flashed sequentially in darkness, and subjects are instructed to make a saccade to the locations of the first, and then the second target 
A

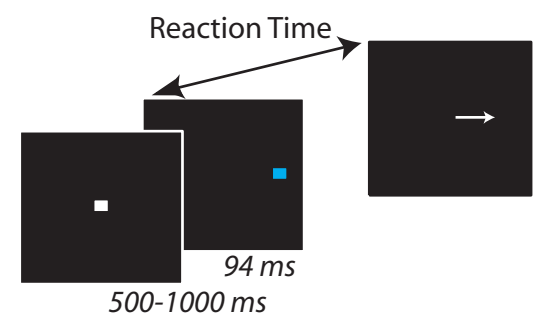

B

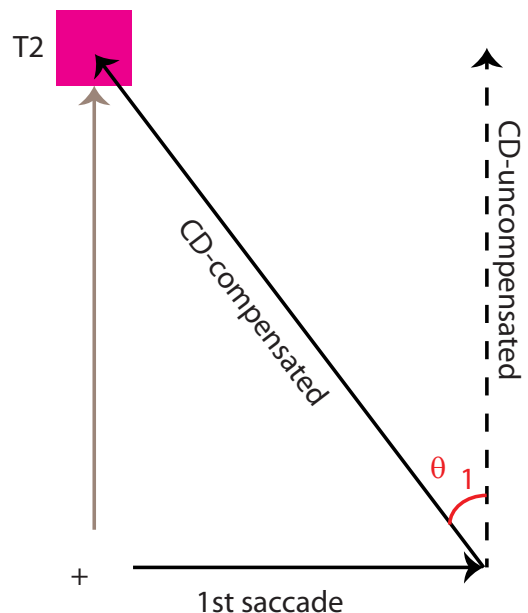

DOUBLE-STEP Trials
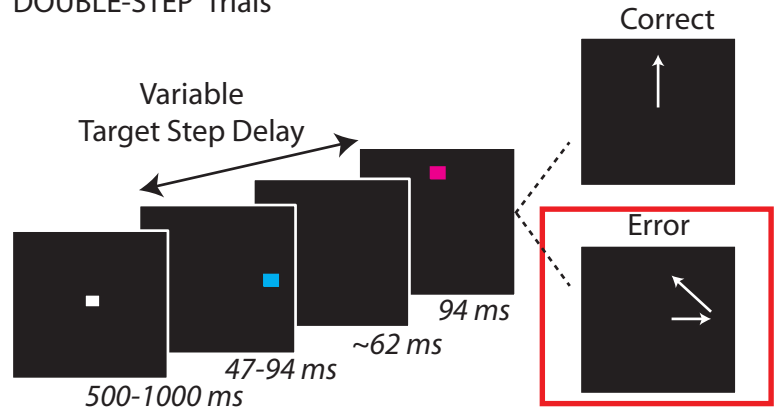

CD for amplitude variability in first saccade

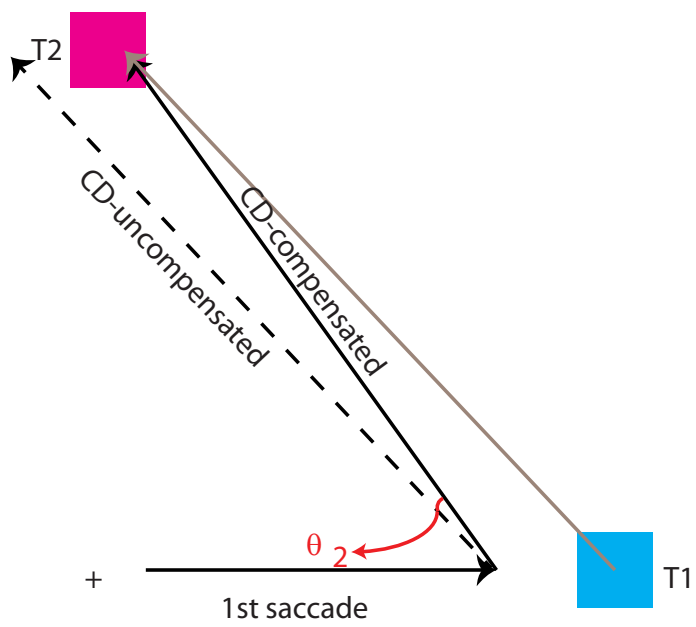

Figure 1. A, Modified double-step task. Arrows indicate the direction of the saccade. Trials began with the presentation of a central fixation spot. After the fixation spot disappeared, a target flashed at a noncentral location. Subjects were instructed to saccade to this location as quickly as possible. On double-step trials, a second target flashed at some variable delay following onset of the first target (target step delay). A target step was the cue for the subject to withhold a saccade to the first target and instead redirect gaze toward the second target. On most double-step error trials, a corrective saccade was made to the second target location. On single-step trials, a second target did not appear. Trial types were randomly interleaved. B, CD Schematic. Left, Schematic of not compensating for the change in eye position brought about by the first saccade. The gray arrow is the saccade vector from fixation to $\mathrm{T} 2$. The dotted arrow represents the saccade that would be made from T1 if the subject had not adjusted for change in position brought about by the first saccade (CD loss-saccade occurrence). Angle $\theta_{1}$ represents the bias in the second saccade vector if the subject had not compensated at all for the first eye movement. Any saccade that fell in the direction between the ideal saccade and saccade indicating no CD was assigned a positive value. Right, Schematic of not compensating for variability in amplitude of the first saccade. The gray arrow is the saccade vector from $\mathrm{T} 1 \mathrm{to} \mathrm{T} 2$. The dotted arrow represents the saccade that would be made from the end point of the first saccade if the subject had not adjusted for error in the endpoint of the first saccade (CD loss-saccade amplitude). Angle $\theta_{2}$ represents the bias in the second saccade vector if the subject had not compensated at all for spatial error in the first saccade endpoint. Any saccade that fell in the direction between the ideal saccade and saccade indicating no $C D$ was assigned a positive value.

(Hallett and Lightstone, 1976; Becker and Jürgens, 1979). To shift gaze to the second target accurately, the subject must account for the first saccade from the fixation point without spatial references or visual feedback. In the double-step task, the measure of interest is spatial accuracy of the second saccade. If the participant fails to compensate for the first saccade due to disrupted $C D$, the second saccade vector deviates from the location of the second target (Fig. $1 B$ ). Healthy humans and nonhuman primates can accurately localize the second target, even when the interval between the first and second saccade is very brief. Further, subjects can also compensate for variations in amplitude of the first saccade (Collins et al., 2009; Joiner et al., 2010). That is, despite making a hypometric or hypermetric saccade to the first target, an accurate saccade to the second target can be executed. This task provides a robust translational bridge for understanding neurophysiological mechanisms of self disturbances in schizophrenia (Sommer and Wurtz, 2002, 2008; Murthy et al., 2007, 2009). To our knowledge, no published studies have investigated the role of CD in the pathophysiology of schizophrenia with the double-step paradigm.
Therefore, we used a modified double-step paradigm (Murthy et al., 2007), which allowed us additional measures of CD beyond mislocalization of the second saccade. In this modified task, we instructed participants to ignore the first target if the second appeared and look only at the second target. The instruction to redirect gaze rather than follow the targets modulates performance of this task (Ray et al., 2004). We manipulated task difficulty such that on approximately one-half of the double-step trials, subjects made rapid saccades to the two targets in succession, as in a typical double-step paradigm. Importantly, on the trials when the first saccade was an error and the second saccade was corrective, we could investigate the quality of $\mathrm{CD}$ to monitor actions in several ways. First, we measured the frequency of error detection and correction. Second, we measured the latency of corrective saccades. CD allows individuals to "know" or sense an impending error before movement initiation. Accordingly, a corrective movement can be executed at very short latencies following an error (Rabbitt, 1966). We expected disrupted CD to result in slower corrective reaction times (RTs). Finally, we asked whether patients with schizophrenia would fail to use CD to lo- 
Table 1. Demographic characteristics of the patient and control groups

\begin{tabular}{lcccc}
\hline & HCs, mean (SD) & SZPs, mean (SD) & Statistic & $p$ \\
\hline Age & $37.6(8.3)$ & $39.9(9.4)$ & $t=0.8$ & 0.5 \\
Sex & $7 \mathrm{~F} / 11 \mathrm{M}$ & $7 \mathrm{~F} / 9 \mathrm{M}$ & $\phi=0.08$ & 0.8 \\
Estimated IQ & $107.7(2.2)$ & $101.1(2.3)$ & $t=2.0$ & 0.05 \\
Years of education & $16.1(2.1)$ & $12.9(1.9)$ & $t=2.4$ & 0.0002 \\
Handedness & $67.8(62.5)$ & $54.4(49.0)$ & $t=0.7$ & 0.5 \\
SFS total & $156.6(14.8)$ & $130.7(17.9)$ & $t=4.6$ & $<0.0001$ \\
SFS employment & $9.9(0.2)$ & $4.7(3.7)$ & $t=6.0$ & $<0.0001$ \\
Years of illness & $\mathrm{n} / \mathrm{a}$ & $19.9(8.3)$ & & \\
CPZ equivalent & $\mathrm{n} / \mathrm{a}$ & $486.6(531.6)$ & & \\
BPRS & $\mathrm{n} / \mathrm{a}$ & $17.2(7.0)$ & & \\
SAPS & $\mathrm{n} / \mathrm{a}$ & $17.0(7.8)$ & & \\
SANS & $\mathrm{n} / \mathrm{a}$ & $24.8(14.4)$ & & \\
\hline
\end{tabular}

SFS, Social Functioning Scale; $n / a$, not applicable.

calize the second target. These data implicate functional pathology in very specific neural circuits that give rise to disrupted CD in schizophrenia.

\section{Materials and Methods}

Participants. Demographic information is presented in Table 1. Sixteen individuals who met the Diagnostic and Statistical Manual of Mental Disorders, Fourth Edition (DSM-IV) criteria for schizophrenia (SZPs) were recruited from outpatient psychiatric facilities in Nashville, TN. Diagnoses were confirmed using the Structured Clinical Interview for DSM-IV (First et al., 1995). All patients were taking either atypical (olanzapine, $n=3$; aripiprazole, $n=2$; clozapine, $n=2$; risperidone, $n=5$; paliperidone, $n=1$; quetiapine, $n=1$; asenapine, $n=1$ ) or typical (thiotixene, $n=1$; haloperidol, $n=1$ ) antipsychotic medication. Some patients were also using antidepressants (citalopram, $n=2$; sertraline, $n=2$; trazadone, $n=4)$, lithium $(n=2)$, and/or anticonvulsants (lamictal, $n=1$; oxcarbazepine, $n=1$ ). Chlorpromazine (CPZ) equivalent antipsychotic dosages were calculated for each patient (Woods, 2003). Eighteen healthy, unmedicated control subjects (HCs) without a personal and family history of DSM-IV Axis I disorders were recruited from the same community by advertisements.

Clinical symptoms were assessed with the Brief Psychiatric Rating Scale (Overall and Gorham, 1962), the Scale for the Assessment of Positive Symptoms (Andreasen, 1984), and the Scale for the Assessment of Negative Symptoms (Andreasen, 1983). Additionally, the Scale for Passivity Phenomena (Spence et al., 1997) was administered to assess current and lifetime passivity symptoms. Social and occupational functioning was assessed by the 79-item Social Functioning Scale (Birchwood et al., 1990), which has seven subscales: social engagement, interpersonal communication, frequency of daily living activities, competence of daily living activities, recreational activities, social activities, and occupational activity. The North American Adult Reading Test (Blair and Spreen, 1989) was used to estimate premorbid IQ. The Modified Edinburgh Handedness Inventory was used to assess handedness (Oldfield, 1971). All participants were screened to exclude substance use, neurological disorders, history of head injury, inability to fixate, and excessive sleepiness. All subjects had normal or corrected-to-normal vision. Groups were matched for age, sex, and handedness. All subjects gave written informed consent approved by the Vanderbilt Institutional Review Board and were reimbursed.

Apparatus and stimuli. Eye position was monitored using the EyeLink II eyetracker (SR Research,) at a sampling rate of $250 \mathrm{~Hz}$ with average gaze position error $<0.5^{\circ}$, noise limited to $<0.01^{\circ}$ root mean square. Saccades were detected on-line using a velocity criterion $(35 \%)$. Subjects were seated $57 \mathrm{~cm}$ from the computer monitor with their head in a chinrest. One aim of this experiment was to examine the integrity of CD signals by measuring the spatial accuracy of the corrective saccade to the final target on double-step trials (Fig. 1B). To eliminate the effect of visual reference cues on saccade localization, the task was performed in darkness by reducing the stimulus presentation computer monitor brightness to the minimum value and using a three-stop neutral density gel filter to block stray monitor light. This technique has been used in prior studies (Park et al., 2003). Subjects were instructed to notify the experimenter, who was seated outside the testing room, if they saw any stray monitor light that revealed the monitor outline as they began to dark-adapt; however, no subjects reported seeing any visual reference cues.

Design and procedure. Subjects performed the saccadic double-step task (Fig. 1A). We used this task to explore both cognitive control of gaze as well as CD in the oculomotor system. Results from our analysis of cognitive control are reported by Thakkar et al. (2015). Sixty percent of the trials were single-step trials. These trials required subjects to fixate on the central fixation spot (white square subtending $0.5^{\circ}$ ) until it disappeared (after a random delay between 500 and $1000 \mathrm{~ms}$ ) and a peripheral target (T1), subtending $1^{\circ}$, flashed for $94 \mathrm{~ms}$ at an alternate location. The first target could be presented at one of eight positions $12^{\circ}$ equidistant from fixation. Subjects were instructed to look directly at the target as quickly as possible. The remaining $40 \%$ of trials were step trials. These trials were initially identical to the no-step trials, but after a variable delay (target step delay; TSD) following initial target presentation, a second target (T2) flashed for $94 \mathrm{~ms}$ at an alternate location. (If the TSD was $<94$ $\mathrm{ms}$, T1 was only presented for the length of the TSD. At TSDs of 47 or 94 $\mathrm{ms}, \mathrm{T} 1$ offset and $\mathrm{T} 2$ onset were simultaneous.) $\mathrm{T} 1$ and $\mathrm{T} 2$ were separated by at least $90^{\circ}$ to minimize the number of saccades landing midway between $\mathrm{T} 1$ and $\mathrm{T} 2$, which occurs more frequently as the angle decreases (for review, see Van der Stigchel and Nijboer, 2011). We further constrained target locations such that $\mathrm{T} 1$ and $\mathrm{T} 2$ were never separated by $180^{\circ}$ (i.e., could not be presented at opposite sides of fixation) as there would be no difference in the saccade vector angle when the subject did or did not use CD to accurately localize the second target. Thus, because targets were presented at one of eight equidistant locations on a circular array, $\mathrm{T} 1$ and $\mathrm{T} 2$ location could be separated by either $90^{\circ}$ or $135^{\circ}$.

The target step instructed subjects to inhibit a saccade to the initial target and instead look toward the second target as quickly as possible. The first and second targets were different isoluminant colors (cyan and magenta, $2.06 \mathrm{~cd} / \mathrm{m}^{2}$, presented on a black background), making it easier to distinguish target order at short TSDs. Color mapping was counterbalanced across subjects. Accuracy (the likelihood of initially directing gaze to the second target location) reduced with increasing TSDs. To manipulate task difficulty TSDs were adjusted trialwise using two independent, interleaved tracking procedures, 2-up/1down (converging near 71\% successful inhibition) and 1-up/2-down (converging near 29\% successful inhibition). This procedure ensures accurate performance on $\sim 50 \%$ of the step trials. The initial TSD was $94 \mathrm{~ms}$. If a particular step trial was part of the 2-up/1-down staircase, TSD increased by $47 \mathrm{~ms}$ if the previous two step trials that were part of that staircase were accurate (first saccade made to T2) and decreased by $47 \mathrm{~ms}$ if the previous step trial in that staircase was inaccurate (first saccade made to T1). Otherwise, the TSD was held constant. Likewise, for trials that were part of the 1-up/2-down staircase, TSD increased by $47 \mathrm{~ms}$ if the previous step trial was accurate, decreased by $47 \mathrm{~ms}$ if the two previous step trials were inaccurate, and was otherwise held constant. The testing session consisted of a practice block of 60 trials, and four experimental blocks of 120 trials each.

For the analysis of CD, we were interested in double-step error trials. These erroneous saccades to the first target are nearly always followed by corrective saccades to the final target. Accordingly, as indices of $\mathrm{CD}$, we measured the incidence and speed of corrective saccades as well as the spatial accuracy of the second saccade, as one would in a standard double-step paradigm. To distinguish corrective saccades from saccades that return the eyes to the central fixation point, the following criteria were used to define corrective saccades: (1) the endpoint of the saccade is closer to T2 than the start of the saccade, (2) the endpoint of the saccade is closer to T2 than to the central fixation location, and (3) the direction of the saccade is closer to the direction necessary for gaze to land on T2 than the direction necessary for gaze to land on the central fixation. Saccadic RT on double-step error trials was calculated as the time between initial target onset and saccade initiation. Corrective saccade latency was measured as the interval between the initiation of the error sac- 
cade and corrective saccade. RT values were log-transformed, using the natural $\log \left(\log _{e}\right)$, to account for non-normality of data.

To examine the spatial accuracy of corrective saccades, we first tested for general directional inaccuracy of the second saccade vector (Joiner et al., 2010). On each trial in which a corrective saccade was produced, we calculated the actual direction of the second saccade and the ideal direction of the second saccade that would have brought the eye upon the second target, based on the endpoint of the initial saccade. For each subject, we plotted the ideal versus actual direction (in polar angle) of each corrective saccade, fit a linear regression model, and compared the slope and $R^{2}$ values across groups. A failure to use CD to correctly localize T2 can be examined in two ways. First, subjects may have failed to take into account that gaze has moved from the fixation point when initiating the second saccade. To measure the degree to which subjects took into account the anticipated change in eye position following a saccade to T1, we measured the angle of deviation between the endpoint of the corrective saccade and the location of T2. Angular deviations in the direction that would be expected if the subject was not using $C D$ to compensate for any change in eye position (i.e., as if making a saccade to T2 from fixation) were assigned a positive value (Fig. $1 B$, left). We refer to these positive deviations as CD loss-saccade occurrence.

Integrity of the $\mathrm{CD}$ mechanisms that support accurate saccades can be measured in a second way on double-step error trials. Saccades to T1 are often slightly hypometric or hypermetric. Both humans and nonhuman primates use CD to adjust for these inaccuracies in the saccade to $\mathrm{T} 1$ when making their saccade to T2. We calculated the degree to which subjects compensated for variations in amplitude of the first saccade by measuring the angle of deviation between the endpoint of the corrective saccade and T2. Angular deviations in the direction that would be expected if the subject were not compensating for spatial inaccuracy in the saccade to $\mathrm{T} 1$ (i.e., making a saccade to $\mathrm{T} 2$ from $\mathrm{T} 1$ ) were assigned a positive value (Fig. $1 B$, right). We refer to these positive deviations as $\mathrm{CD}$ loss-saccade amplitude.

Given the literature documenting asymmetries in spatial attention in schizophrenia, we also examined the influence of T1 hemifield on measures of CD integrity. For this analysis, we excluded trials in which the initial saccade was vertical. Analyses of RT and biases in the second saccade endpoint toward CD loss were conducted with the hemifield of $\mathrm{T} 1$ as a factor in the model.

Finally, to control for the possibility that putative group differences in the endpoint accuracy of the saccade to T2 are accounted for by differences in the dynamics of the initial saccade to T1, we calculated the amplitude of T1 and the degree to which the direction of the saccade to $\mathrm{T} 1$ was biased in the direction of T2. Saccades biased in the direction of T2 were assigned a positive value.

Statistical methods. Fisher's exact tests, independent $t$ tests, and repeated-measures ANOVAs were used where appropriate. Spearman rank-correlation coefficients were calculated between symptoms and task performance. All tests were two-tailed.

\section{Results}

\section{Error correction rate}

An independent $t$ test was used to compare the percentage of corrected double-step error trials across groups. SZPs corrected fewer errors than HCs (HC: mean $=88.1 \%$, SD = 13.4; SZP: mean $\left.=78 \%, \mathrm{SD}=13.8 ; t_{(32)}=2.2, p=0.04\right)$, suggesting impaired action monitoring.

\section{Error correction speed}

Cumulative RT distributions are presented in Figure 2. To examine corrective saccade latency compared with error saccade latency, as well as putative group differences in corrective saccade latency, a repeated-measures ANOVA was conducted on mean log-transformed RT, with response type (corrective, error) and angle between targets $\left(90^{\circ}, 135^{\circ}\right)$ as within-subjects variables and diagnostic group as a between-subjects variable. We found no

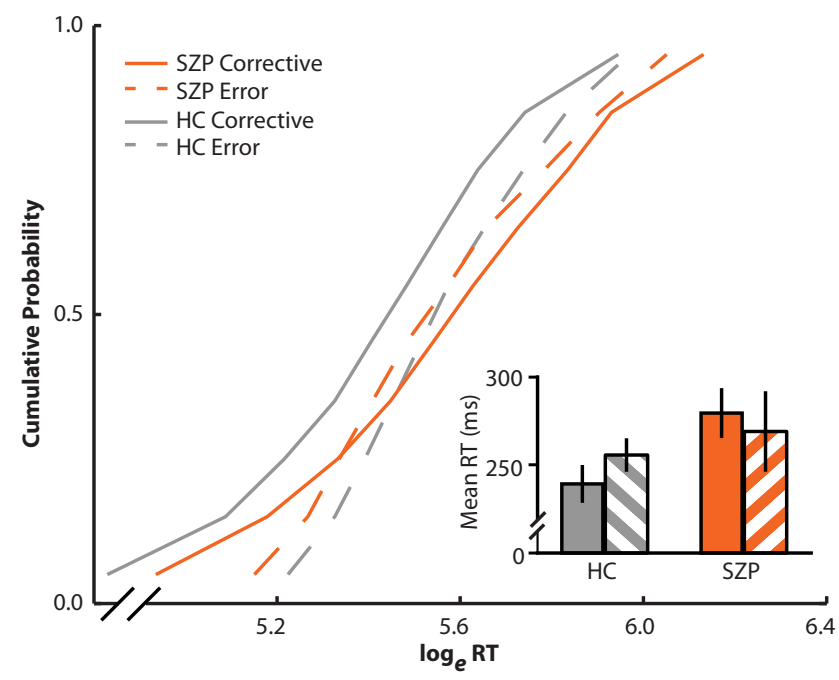

Figure 2. Error and corrective saccade RTs. RTs were transformed using the natural log $\left(\log _{e}\right)$. Vincentized reaction time distributions for error (dotted lines) and corrective saccades (solid lines) on double-step trials. HCs are depicted in gray and SZPs are depicted in orange. Error saccades were measured as the time between $\mathrm{T} 1$ onset and the onset of the first saccade. Corrective saccades were measured as the time between the onset of the error saccade and the onset of the corrective saccade. For each participant, RTs for error and corrective saccades were binned into deciles. Decile means were averaged across subjects to create the groupaveraged vincentized RT distributions. Inset, Mean RTs for corrective (solid bars) and error (striped bars) saccades are presented.

main effect of either group $\left(F_{(1,32)}=2.2, p=0.15\right)$ or response type $\left(F_{(1,32)}=3.1, p=0.09\right)$. Importantly, however, we found a significant group-by-response type interaction effect $\left(F_{(1,32)}=\right.$ $4.2, p=0.05)$. In HCs, corrective saccades were significantly faster than the initial error saccade (corrective: mean $=239 \mathrm{~ms}$, $\mathrm{SD}=41 \mathrm{~ms}$; error: mean $=256 \mathrm{~ms}, \mathrm{SD}=36 \mathrm{~ms} ; t_{(17)}=3.7, p=$ 0.002), but we found no difference between saccade types in SZPs (corrective: mean $=279 \mathrm{~ms}, \mathrm{SD}=53 \mathrm{~ms}$; error: mean $=269 \mathrm{~ms}$, $\left.\mathrm{SD}=88 \mathrm{~ms} ; t_{(15)}=0.2, p=0.81\right)$. Further, we found no difference in error saccade latency between groups $\left(t_{(32)}<0.1, p>0.99\right)$, but corrective saccades were significantly slower in SZPs than HCs $\left(t_{(32)}\right.$ $=2.2, p=0.04)$. We found no effect of angle of separation between targets. These data suggest that SZPs fail to use CD to plan a corrective movement in anticipation of making an error.

\section{Corrective saccade spatial accuracy}

Eye position traces from two representative participants for all double-step trials in which a saccade to T1 was followed by a saccade to T2 are presented in Figure 3.

\section{Ideal versus observed saccade direction}

For each subject, the relationship between the direction of the ideal saccade to the second target compared with the observed saccade direction was quantified by fitting a linear model (Fig. $4)$. Goodness of fit $\left(R^{2}\right)$ and slope values were submitted to separate repeated-measures ANOVAs with angle between T1 and T2 entered as within-subject variables and group entered as a between-subjects variable. We found no effect of group $\left(F_{(1,32)}=0.3, p=0.60\right)$, angle between targets $\left(F_{(1,32)}=2.9\right.$, $p=0.10)$, or group-by-separation angle interaction $\left(F_{(1,32)}=\right.$ $0.5, p=0.48)$ on slope. We found, however, a significant effect of group $\left(F_{(1,32)}=4.1, p=0.05\right)$ and marginal effect of angle $\left(F_{(1,32)}=3.2, p=0.08\right)$ on $R^{2}$ values. Importantly, we found also a significant group-by-separation angle effect $\left(F_{(1,32)}=\right.$ $8.8, p=0.006) \cdot R^{2}$ values (noted in Fig. 4 ) were lower in SZPs 
A

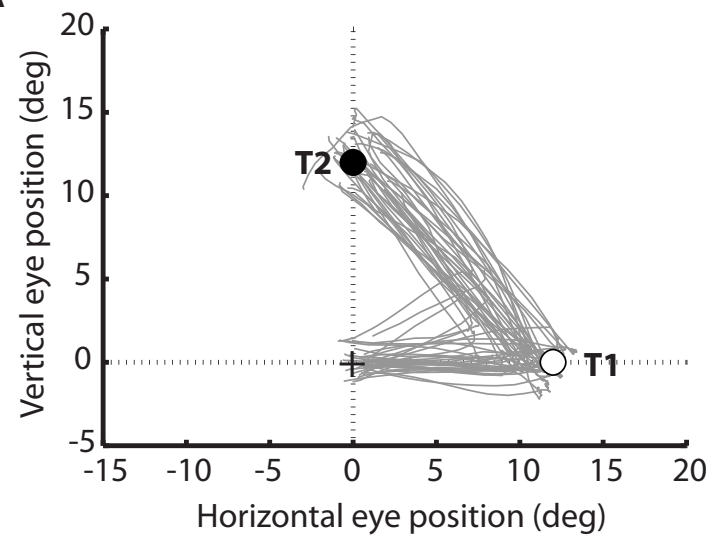

B

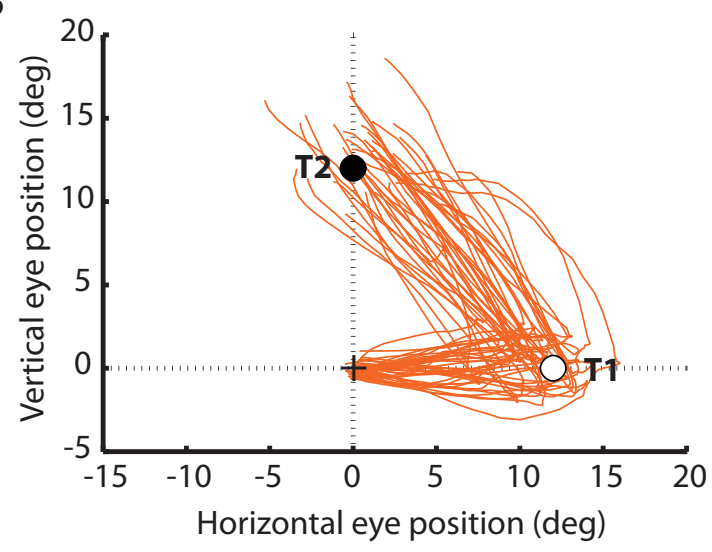

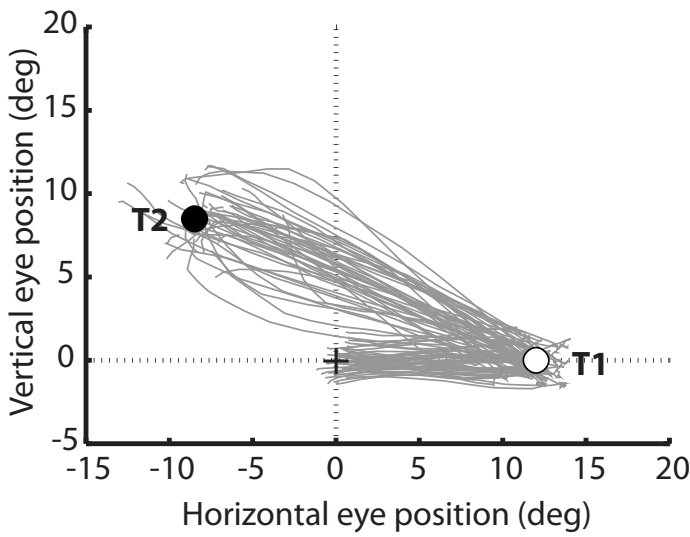

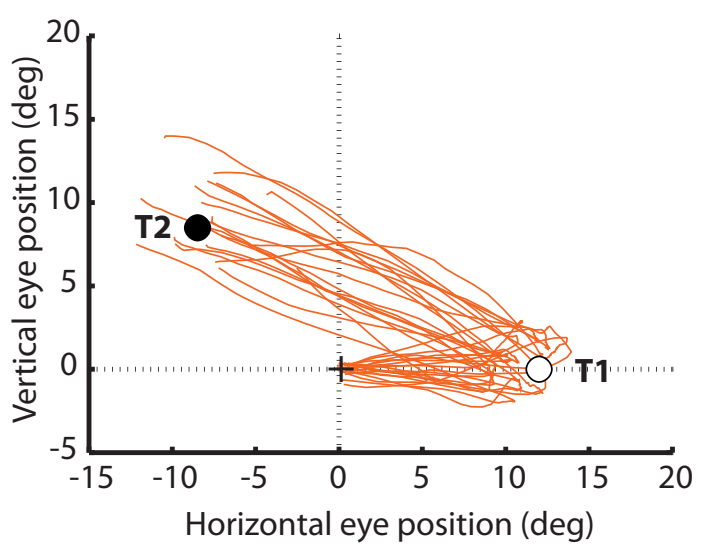

Figure 3. Eye position traces for a representative $\mathrm{HC}(\boldsymbol{A})$ and SZP $(\boldsymbol{B})$. The eye position between the initiation of the first saccade toward T1 (empty circle) and the termination of the second saccade toward T2 (filled circle) are depicted for each trial in which successive saccades to T1 and T2 were produced. Plots are separated for $90^{\circ}$ (left) and $135^{\circ}$ (right) $\mathrm{T} 1-\mathrm{T} 2$ angles. Saccade vectors to different target locations were normalized into the same space.
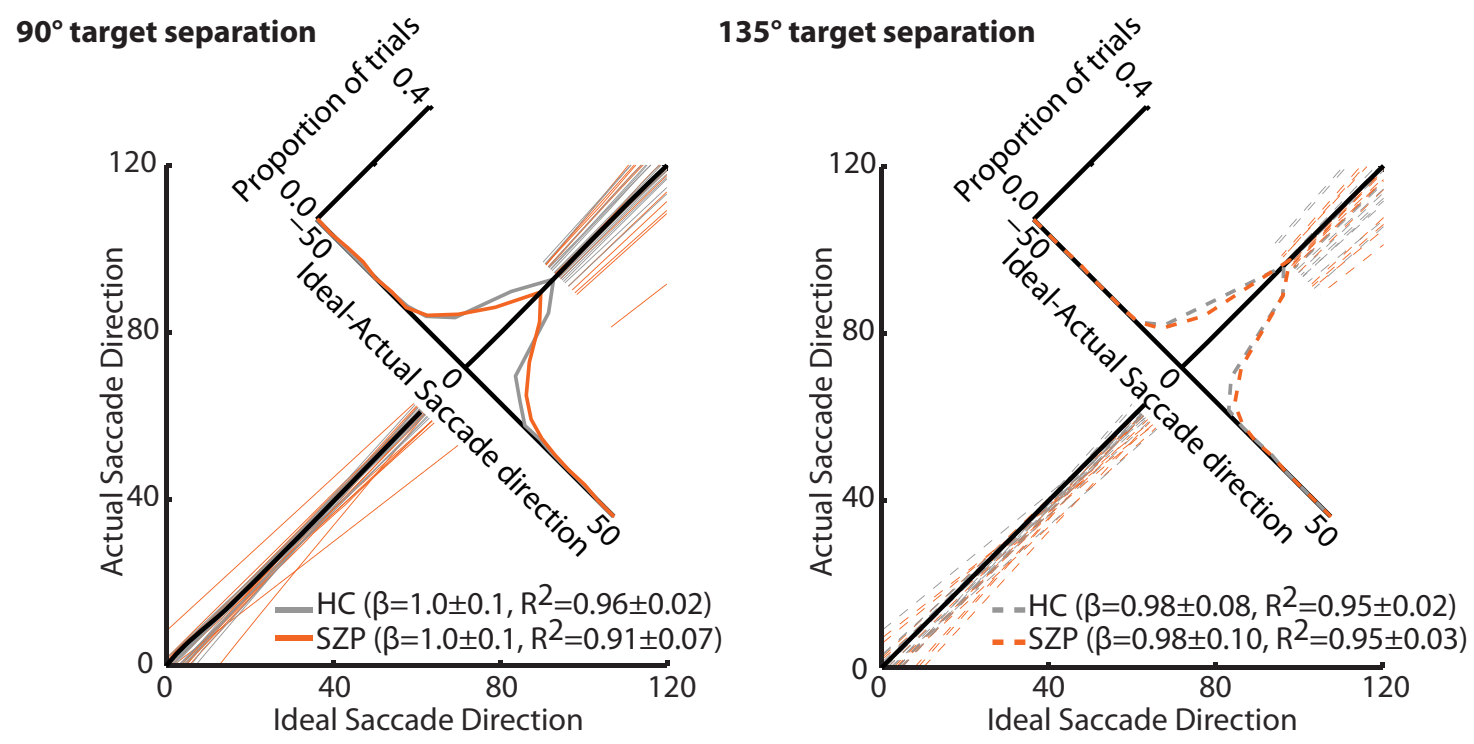

Figure 4. Ideal versus actual saccade vector. For each participant, regression lines were fit to actual corrective saccade vector angle plotted as a function of ideal saccade vector angle when targets were separated by $90^{\circ}$ (left) and $135^{\circ}$ (right) for HCs (gray) and SZPs (orange). Individual regression lines are depicted. The black line represents the line of unity. Accompanying the regression lines is a histogram of the signed differences between the ideal and actual saccade direction, separately for controls and patients.

than HCs when targets were separated by $90^{\circ}\left(t_{(32)}=2.6, p=\right.$ $0.01)$, but not $135^{\circ}\left(t_{(32)}=0.2, p=0.81\right)$. These data indicate more variability in degree to which SZPs use CD to accurately localize the second target.

\section{CD influence on corrective saccade endpoint}

Figure 5 shows single trial examples of biases in the second saccade endpoint toward not compensating for the first saccade (CD loss-saccade occurrence; Fig. 5A) and not compensating hypo- or 
hypermetricity of the first saccade (CD loss-saccade amplitude; Fig. $5 B$ ) in one SZP. Figure 6 quantifies the magnitude of $\mathrm{CD}$ guiding corrective saccades. We submitted both CD loss-saccade occurrence and CD loss-saccade amplitude to two separate repeated-measures ANOVAs with angle of separation between $\mathrm{T} 1$ and $\mathrm{T} 2$ entered as a within-subjects variable and group entered as a between-subjects variable. Significance was evaluated at a Bonferronicorrected $\alpha$-level of $0.025(0.05 / 2)$, to correct for multiple testing.

For CD loss-saccade occurrence (Fig. $6 A)$, we found a significant effect of target separation $\left(F_{(1,32)}=0.02\right)$. Even though the main effect of group did not reach significance after Bonferroni correction $\left(F_{(1,32)}=4.4, p=0.04\right)$, we found a significant group-by-target separation interaction $\left(F_{(1,32)}=9.3, p=0.004\right)$. Planned independent $t$ tests indicated that SZPs showed less CD compensation than HCs when targets were separated by $90^{\circ}$ ( $\mathrm{HC}$ : mean $=0.5^{\circ}, \mathrm{SD}=2.1^{\circ}$; SZP: mean $=$ $\left.3.1^{\circ}, \mathrm{SD}=2.6^{\circ} ; t_{(32)}=3.1, p=0.004\right)$ but $\operatorname{not} 135^{\circ}\left(t_{(32)}=0.4, p=0.67\right)$.

To quantify the degree to which subjects fully compensated for the occurrence of the first saccade, for each trial we calculated the angle between the vector of the ideal saccade and the vector resulting from no CD (Fig. $1 B, \theta_{1}$ ). We calculated percentage compensation as the angle between the actual saccade vector and the vector resulting from no $\mathrm{CD}$ divided by $\theta_{1} ; 100 \%$ compensation indicates complete CD producing an accurate saccade to $\mathrm{T} 2$, and $0 \%$ compensation indicates no CD compensating for the first saccade. When targets were separated by $90^{\circ}$, we found nearly complete compensation in HCs $($ mean $=99.8 \%$, SD $=7.4 \%)$, but not in SZPs (mean $=91.6 \%, \mathrm{SD}=8.8 \%$ ).

When targets were separated by $135^{\circ}, \mathrm{CD}$ compensation was more similar between HCs (mean $=95.8 \%, \mathrm{SD}=10.0 \%)$ and SZPs $(99.9 \%, \mathrm{SD}=10.4 \%)$. When targets were separated by $90^{\circ}$, SZPs compensated $\sim 8 \%$ less than HCs for the occurrence of the first saccade.

The robust group-by-target separation interaction was unexpected. Given the greater distance between targets separated by $135^{\circ}$, we tested whether schizophrenia patients might have adjusted saccade trajectory midflight to direct gaze closer to T2. We measured the initial saccade trajectory between fixation and instantaneous eye position $12 \mathrm{~ms}$ following saccade initiation (Van der Stigchel et al., 2006). Although the initial saccade trajectory reflected less $\mathrm{CD}$ compensation, the initial trajectory still showed a significant group-by-angle interaction effect $\left(F_{(1,32)}=5.2, p=\right.$ $0.03)$. That is, even at initiation of the corrective saccade, $C D$ had reduced influence when targets were separated by $90^{\circ}$ compared to $135^{\circ}$ in SZPs.

For CD loss-saccade amplitude (Fig. $6 B$ ) we found no significant effect of group $\left(F_{(1,32)}=0.05, p=0.82\right)$, separation angle
$\left(F_{(1,32)}=0.59, p=0.44\right)$, or group-by-separation angle interaction $\left(F_{(1,32)}=2.2, p=0.15\right)$. Thus, SZPs showed a loss of CD for making any saccade toward T1, but did not show evidence of a loss of CD for not having made the ideal saccade to T1.

\section{Spatial asymmetries in CD}

To examine saccade latencies as a function of T1 hemifield, a repeated-measures ANOVA was conducted on log-transformed RTs, with hemifield (left, right), response type (corrective, error) and angle between targets $\left(90^{\circ}, 135^{\circ}\right)$ entered as within-subjects as factors and group entered as a between-subjects factor. We found no significant effect of saccade direction, nor any interaction effects involving saccade direction.

We also examined spatial accuracy of the corrective saccade endpoint as a function of hemifield. Both CD loss-saccade occurrence and CD loss-saccade amplitude were submitted to a repeatedmeasures ANOVA with initial saccade direction and angle between targets entered as within-subjects factors, and group entered as a between-subjects factor. Significance of both of these ANOVAs was 


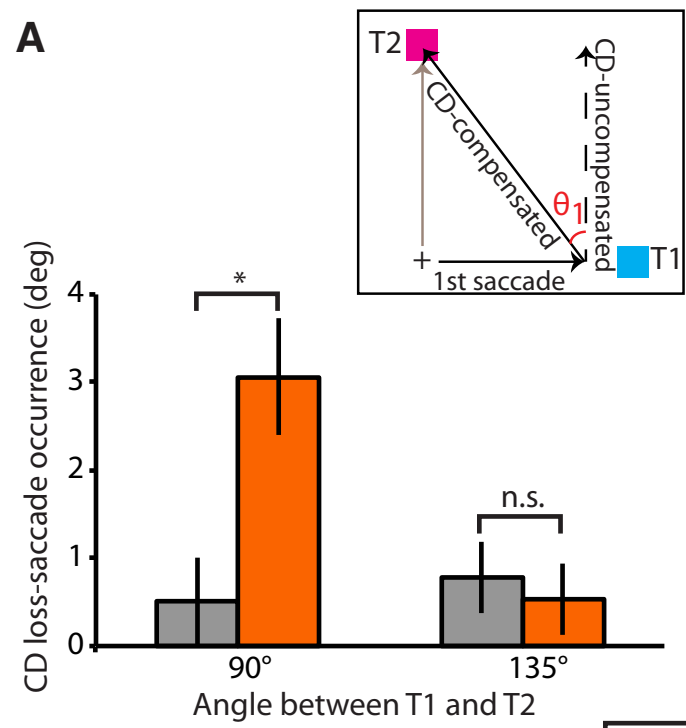

B

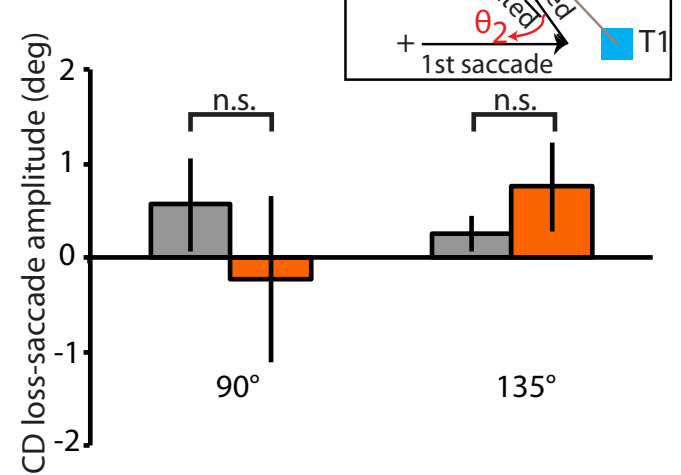

Angle between $\mathrm{T} 1$ and $\mathrm{T} 2$

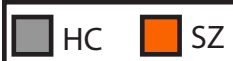

Figure 6. Loss of CD. $\boldsymbol{A}$, Mean CD loss-saccade occurrence ( \pm SE) and (B) mean CD loss-saccade amplitude ( $\pm S E$ ) separated by target separation angle for HCs (gray) and SZPs (orange). n.s., $p>$ $0.05 ;{ }^{*} p<0.05$.

A

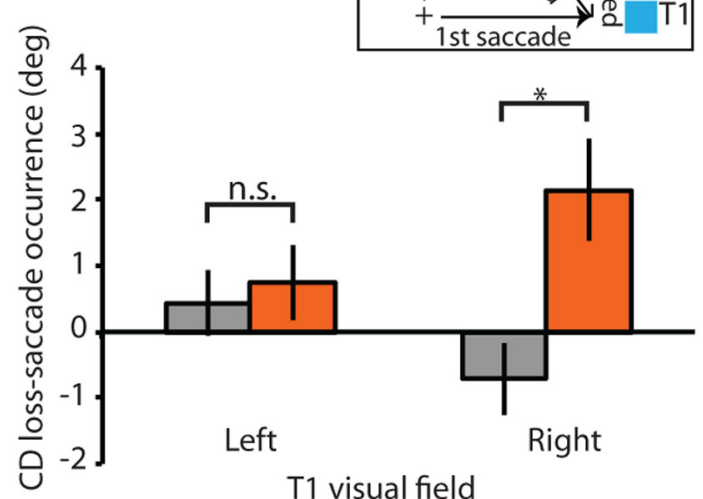

B
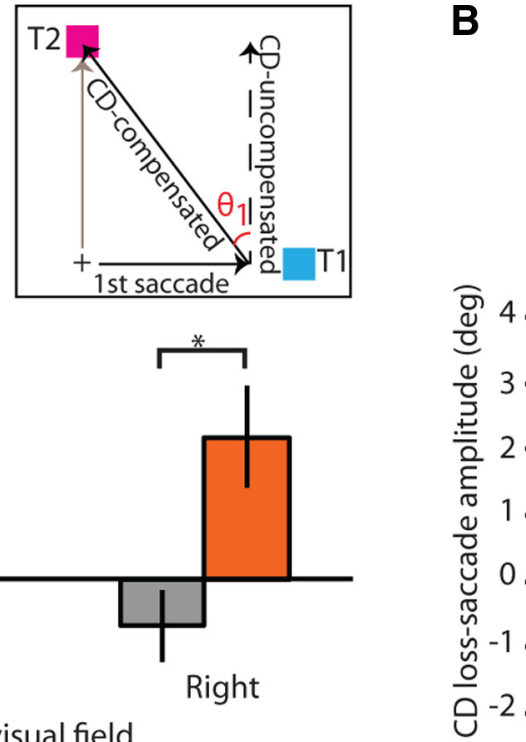

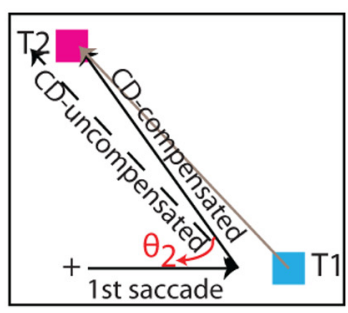

1st saccade

HC $\square$ sZP

Figure 7. Loss of $C D$ as a function of target hemifield presentation. $\boldsymbol{A}$, Mean CD loss-saccade occurrence ( $\pm S E)$ and $(\boldsymbol{B})$ mean CD loss-saccade amplitude ( \pm SE) separated by visual hemifield of T1 for HCs (gray) and SZPs (orange). n.s., $p>0.05 ;{ }^{*} p<0.05$.

evaluated at a Bonferroni-corrected $\alpha$-level of $0.025(0.05 / 2)$, to correct for multiple testing. For CD loss-saccade occurrence (Fig. $7 A$ ), we found no main effect of saccade direction, and the group-bysaccade direction interaction effect did not meet significance after correcting for multiple testing $\left(F_{(1,32)}=4.1, p=0.05\right)$. We were intrigued, however, by this trend toward a significant interaction and performed planned between-group comparisons. In SZPs, we found a greater bias in second saccade endpoint toward no influence of CD to compensate for the first saccade relative to controls when the first saccade was rightward $\left(\mathrm{HC}\right.$ : mean $=-0.7^{\circ}, \mathrm{SD}=2.3^{\circ} ; \mathrm{SZP}$ : mean $=$ $\left.2.1^{\circ}, \mathrm{SD}=3.0^{\circ} ; t_{(32)}=3.1, p=0.004\right)$ but not leftward $\left(t_{(32)}=0.4\right.$, $p=0.69)$.
For CD loss-saccade amplitude (Fig. $7 B$ ), we found a significant group-by-saccade direction interaction effect $\left(F_{(1,32)}=6.8, p=\right.$ $0.01)$. In SZP, bias in second saccade endpoint was greater when T1 was in the left versus right hemifield (left: mean $=1.4^{\circ}, \mathrm{SD}=3.5^{\circ}$; right: mean $\left.=-0.5^{\circ}, \mathrm{SD}=3.3^{\circ} ; t_{(15)}=2.3, p=0.04\right)$. This effect was not present in $\mathrm{HCs}\left(t_{(17)}=0.8, p=0.4\right)$. However, there were no significant group differences in bias for either T1 hemifield (right: $t_{(32)}=1.8, p=0.09$; left: $\left.t_{(32)}=0.9, p=0.36\right)$.

\section{Control analyses}

To ensure that group differences in the bias of the corrective saccade endpoint in the direction predicted by loss of CD were 
A

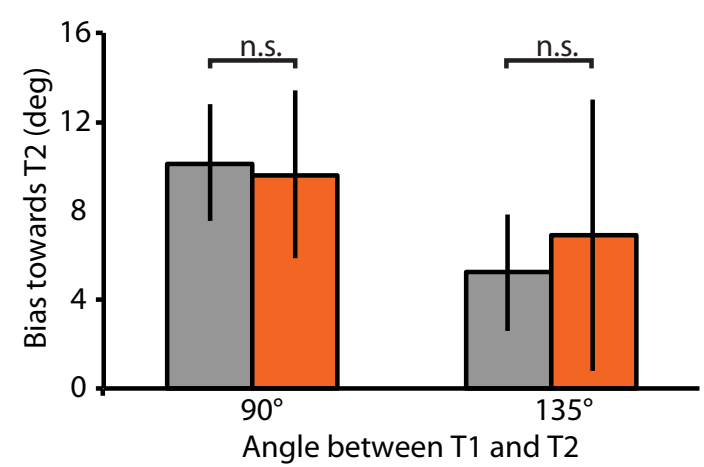

B

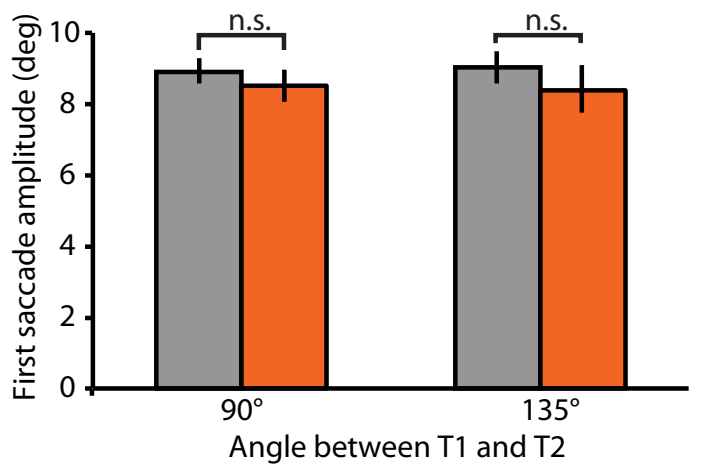

Figure 8. Dynamics of first saccade on error double-step trials, separated by angle of target separation. $\boldsymbol{A}$, Mean bias ( $\pm \mathrm{SE}$ ) in the first saccade vector angle in the direction of T2. $\boldsymbol{B}$, Mean amplitude ( \pm SE) of the first saccade in degrees of visual angle (right) for HCs (gray) and SZPs (orange). n.s., $p>0.05$.

not due to group differences in the dynamics of the saccade to T1, we compared the degree to which the first saccade was biased toward T2 (Fig. 8A) and the first saccade amplitude (Fig. 8B) across groups. Repeated-measures ANOVAs were conducted on each of these variables, including separation angle between T1 and T2 as within-subjects variables and group as a betweensubjects variable. For saccade amplitude, we found no effect of group $\left(F_{(1,32)}=1.4, p=0.24\right)$, separation angle $\left(F_{(1,32)}<0.1, p>\right.$ $0.99)$, or group-by-separation angle interaction $\left(F_{(1,32)}=0.5\right.$, $p=0.49)$. For directional error in the first saccade, we found a significant effect of separation angle $\left(F_{(1,32)}=5.9, p<0.0001\right)$. Saccades to T1 were more biased in the direction of T2 when targets were separated by $90^{\circ}\left(\right.$ mean $=9.9^{\circ}, \mathrm{SD}=5.8^{\circ}$ ) versus $135^{\circ}\left(\right.$ mean $\left.=6.0^{\circ}, \mathrm{SD}=5.8^{\circ}\right)$. Importantly, however, we found no effect of group $\left(F_{(1,32)}=0.1, p=0.75\right)$, or group-byseparation angle interaction $\left(F_{(1,32)}=1.9, p=0.18\right)$.

\section{Symptom, social functioning, and medication correlations}

Correlations were performed between measures of symptom severity, social functioning, and standardized medication dose and indices of CD: percentage corrected responses, log-transformed corrective saccade RT, the $R^{2}$ and slope values for the linear function plotting ideal versus observed second saccade direction, CD loss-saccade occurrence, and CD loss-saccade amplitude. Correlations with the latter two measures were performed separately for the $90^{\circ}$ and $135^{\circ}$ target configurations. No significant correlations were observed between symptom severity and social functioning and any of double-step task performance measures. We found a modest positive correlation between CPZ dose and $R^{2}$ value of the ideal-actual saccade direction function $(r=0.6, p=$ 0.03 ), but only in the $135^{\circ}$ target configuration, in which we did not observe any group differences.

\section{Discussion}

Using a double-step saccade task, we report multiple lines of evidence demonstrating disrupted saccadic CD in schizophrenia. Most crucially, when schizophrenia patients make saccades in rapid succession, they fail to compensate for the displacement of the first saccade. This systematic mislocalization has never been shown before in schizophrenia and provides clear evidence of disrupted oculomotor CD.

This mislocalization of the second target cannot be explained by differences in the dynamics of the saccade to the first target.
Schizophrenia patients were unimpaired in the amplitude of the first saccade or in the degree to which the first saccade was biased toward the second target.

Likewise, this mislocalization is unlikely to be due only to the documented working memory deficits in schizophrenia (Park and Holzman, 1992) because the task included no delay period. Also, unlike symmetrically greater variability of saccade endpoints around the second target predicted by impaired working memory (White et al., 1994), we saw a systematic bias in the mislocalization of T2 in the direction predicted by an impaired CD.

Interestingly, mislocalization of T2 was highly dependent on the arrangement of $\mathrm{T} 1$ and $\mathrm{T} 2$. Loss of CD was clearer when targets were separated by $90^{\circ}$ than $135^{\circ}$. We are unaware of any studies that have investigated the influence of angle or distance between targets on second saccade accuracy in such tasks. Thus, the basis of this target separation effect remains unclear. In previous double-step experiments, targets were separated by $<90^{\circ}$ or positioned on the horizontal meridian. We considered the hypothesis that greater distance between $\mathrm{T} 1$ and $\mathrm{T} 2$ when targets were separated by $135^{\circ}$ allowed subjects to correct midflight an initially errant saccade trajectory (Minken et al., 1993); however, an effect of target separation was present even in the initial saccade trajectory. The difference in the direction of the CDcompensated saccade from $\mathrm{T} 1$ to $\mathrm{T} 2$ and the $\mathrm{CD}$-uncompensated saccade was greater when targets were separated by $90^{\circ}$ than $135^{\circ}$ $\left(45^{\circ}\right.$ vs $\left.22.5^{\circ}\right)$, so measurements may have been more sensitive to deviations in the second saccade vector with the $90^{\circ}$ target configuration.

We also observed a statistical trend toward spatial asymmetry of CD, in schizophrenia. Patients showed attenuated influence of $\mathrm{CD}$ when $\mathrm{T} 1$ was in the right visual field. Right visual hemifield abnormalities have been reported for response latencies (Gur, 1978), spatial attention (Posner et al., 1988), and memory-guided saccades (Park, 1999). Interestingly, among right-handed schizophrenia patients, visual hallucinations are most often seen in the right visual field (Bracha et al., 1985).

We observed other evidence for abnormal CD in schizophrenia. On double-step trials, subjects were instructed to look immediately at the second target. Trials in which subjects first looked at T1 were errors. CD is the purported mechanism for internally monitoring motor plans to predict an upcoming erroneous response and plan corrections in parallel with the error 
response (Coles et al., 1985; Ray et al., 2004; Murthy et al., 2007; Sharika et al., 2008). Consistent with this notion, corrective responses in healthy controls were faster than errors. In patients, however, we found no difference between errors and corrective response latencies, suggesting reduced influence of CD. Thus, despite equal error saccade latencies across groups, patients were slower at correcting these errors. Providing further evidence for disrupted CD, schizophrenia patients corrected fewer errors.

Findings regarding post-error behavioral adjustments in schizophrenia are mixed; both intact (Kopp and Rist, 1994, 1999; Brownstein et al., 2003; Morris et al., 2006; Polli et al., 2006, 2008; Reuter et al., 2006) and impaired adjustments during cognitive tasks have been reported (Malenka et al., 1982, 1986; Frith and Done, 1989; McDowell and Clementz, 1997; Turken et al., 2003; Waters et al., 2009). One explanation for our findings is that we removed all visual reference cues, thus placing particularly strong demands on internal monitoring via CD. Thus, in contrast with previous studies, subjects could not rely on sensory information to shift gaze in space.

Combined, these findings are consistent with past reports of impaired generation, transmission, or use of CD in schizophrenia to modulate visual (Thaker et al., 1996; Lindner et al., 2005; Spering et al., 2013; Richard et al., 2014), auditory (Ford et al., 2001a,b,c, 2004; Ford and Mathalon, 2004), and tactile (Blakemore et al., 2000) information processing.

The significance of our study is the precision with which CD can be mapped to specific circuits in the primate brain. Accordingly, these findings offer a direct translational link between neurophysiological data in animals and behavioral data in patient populations. Strong evidence demonstrates that neurons in the mediodorsal (MD) thalamus convey CD signals generated by movement neurons in the superior colliculus (SC) to the frontal eye fields (FEFs; Sommer and Wurtz, 2002, 2004, 2008). Following inactivation of MD thalamus, nonhuman primates performing a double-step task showed reduced influence of $\mathrm{CD}$ through systematic mislocalization of the second target, paralleling our observation in schizophrenia patients. Double-step task performance is also impaired in thalamic lesion patients (Gaymard et al., 1994; Bellebaum et al., 2005; Ostendorf et al., 2010). Thus, functional alterations in this SC-MD-FEF pathway could result in abnormal incidence, latency, or precision of saccadic CD signals in schizophrenia patients. One very important property of signals sent to the thalamus either from cortex or lower brain regions is that they are most often also sent to motor centers (Guillery and Sherman, 2002). Accordingly, thalamocortical relays have been conceptualized as "monitoring" ongoing motor commands. Although speculative, the thalamus might be a relay hub for transmitting CD signals across the cortex, and dysfunctions in modality-specific thalamocortical pathways might give rise to the heterogeneity of psychotic experiences.

Given the role of the thalamus in relaying information linking multiple brain regions, altered thalamic function would contribute to abnormal functional connectivity (Andreasen et al., 1998; Stephan et al., 2006). Interestingly, there are recent reports of abnormal functional connectivity of the MD thalamus in schizophrenia that are related to symptoms theoretically linked to abnormal CD. Woodward et al. (2012) observed hypoconnectivity between MD thalamus and prefrontal cortex at resting state in schizophrenia. Attesting to the clinical relevance of such corticothalamic connectivity, decreased functional connectivity has been shown between auditory cortex and MD thalamus in individuals that experience auditory hallucinations (Shinn et al., 2013), individuals with psychotic bipolar disorder show greater alterations in functional connections between MD thalamus and cortex than those with nonpsychotic bipolar disorder, (Anticevic et al., 2014), and altered microstructural integrity of the thalamus has been related to alien control delusions in schizophrenia patients (Sim et al., 2009). Thus, abnormal thalamocortical connections that disrupt CD may contribute to blurred self-other boundaries and vulnerability to psychosis.

Neurophysiological evidence also points to the importance of parietal cortex for the spatial updating needed for double-step task performance. Visually responsive neurons in lateral intraparietal sulcus predictively update their receptive field properties based on an impending saccade (for review, see Hall and Colby, 2011), modulated by CD signals from MD thalamus (Wurtz, 2008). Parietal lesions disturb the second saccade trajectory during the double-step task (Duhamel et al., 1992; Heide et al., 1995; Pisella et al., 2011), which suggests the important role of the parietal visual neurons in updating their receptive properties based on CD signals.

These results have caveats. First, the influence of antipsychotic medication on CD is unclear; however, it is unlikely that CD disruptions were caused by medication; none of the CD measures varied with medication dose. Moreover, disrupted CD is argued to engender the psychotic symptoms that antipsychotics attenuate (Feinberg, 1978; Frith, 1992). Thus, antipsychotics, if anything, should improve CD. This point, however, brings us to our second limitation. Although we conjecture a link between CD disturbances and psychotic symptoms, we observed no correlations between symptoms and CD measures. This is not unprecedented (Ford and Mathalon, 2012; Ford et al., 2012). The absence of symptom correlations could indicate that CD disturbances reflect symptom vulnerability, rather than expression. Alternatively, symptoms interviews may be inadequate; they lack key questions about psychotic experiences that are closely aligned to CD abnormalities, such as body aberrations (Chapman et al., 1978; Thakkar et al., 2011). Finally, individuals with schizophrenia did not show evidence for a complete loss of CD. When targets were separated by $90^{\circ}$, patients showed, on average, an $8 \%$ loss of CD compared with HCs. Although the magnitude of this effect is modest, primates with pharmacological MD thalamus inactivation performing the double-step task also showed only a partial loss of CD (19\%; Sommer and Wurtz, 2004). To explain these partial deficits, Sommer and Wurtz (2004) highlight the multiple potential thalamic and nonthalamic routes for CD signals to reach cortex and the possible compensatory use of proprioception to guide saccadic eye movements.

In conclusion, using the double-step saccade task used for single-cell neurophysiological studies of CD transmission, we found strong evidence for abnormal CD in patients with schizophrenia. Our findings provide a direct translational bridge to understanding the biological underpinnings of psychotic experiences in schizophrenia and highlight the role of CD beyond basic sensorimotor processing.

\section{References}

Andreasen NC (1983) The scale for the assessment of negative symptoms (SANS). Iowa City, IA: University of Iowa.

Andreasen NC (1984) The scale for the assessment of positive symptoms (SAPS). Iowa City, IA: University of Iowa.

Andreasen NC, Paradiso S, O'Leary DS (1998) “Cognitive dysmetria” as an integrative theory of schizophrenia: a dysfunction in cortical-subcorticalcerebellar circuitry? Schizophr Bull 24:203-218. CrossRef Medline

Anticevic A, Yang G, Savic A, Murray JD, Cole MW, Repovs G, Pearlson GD, Glahn DC (2014) Mediodorsal and visual thalamic connectivity differ in schizophrenia and bipolar disorder with and without psychosis history. Schizophr Bull 40:1227-1243. CrossRef Medline 
Becker W, Jürgens R (1979) An analysis of the saccadic system by means of double step stimuli. Vision Res 19:967-983. CrossRef Medline

Bellebaum C, Daum I, Koch B, Schwarz M, Hoffmann KP (2005) The role of the human thalamus in processing corollary discharge. Brain 128:11391154. CrossRef Medline

Birchwood M, Smith J, Cochrane R, Wetton S, Copestake S (1990) The social functioning scale: the development and validation of a new scale of social adjustment for use in family intervention programmes with schizophrenic patients. Br J Psychiatry 157:853-859. CrossRef Medline

Blair JR, Spreen O (1989) Predicting premorbid IQ: a revision of the national adult reading test. Clin Neuropsychol 3:129-136. CrossRef

Blakemore SJ, Wolpert D, Frith C (2000) Why can't you tickle yourself? Neuroreport 11:R11-R16. CrossRef Medline

Bracha HS, Cabrera FJ Jr, Karson CN, Bigelow LB (1985) Lateralization of visual hallucinations in chronic schizophrenia. Biol Psychiatry 20:11321136. CrossRef Medline

Brownstein J, Krastoshevsky O, McCollum C, Kundamal S, Matthysse S, Holzman PS, Mendell NR, Levy DL (2003) Antisaccade performance is abnormal in schizophrenia patients but not in their biological relatives. Schizophr Res 63:13-25. CrossRef Medline

Chapman LJ, Chapman JP, Raulin ML (1978) Body-image aberration in schizophrenia. J Abnorm Psychol 87:399-407. CrossRef Medline

Coles MG, Gratton G, Bashore TR, Eriksen CW, Donchin E (1985) A psychophysiological investigation of the continuous flow model of human information processing. J Exp Psychol Hum Percept Perform 11:529553. CrossRef Medline

Collins T, Rolfs M, Deubel H, Cavanagh P (2009) Post-saccadic location judgments reveal remapping of saccade targets to non-foveal locations. J Vis 9(5):29 1-9. CrossRef Medline

Duhamel JR, Goldberg ME, Fitzgibbon EJ, Sirigu A, Grafman J (1992) Saccadic dysmetria in a patient with a right frontoparietal lesion. Brain 115: 1387-1402. CrossRef Medline

Feinberg I (1978) Efference copy and corollary discharge: implications for thinking and its disorders. Schizophr Bull 4:636-640. CrossRef Medline

First MB, Spitzer RL, Gibbon M, Williams JBW (1995) Structured clinical interview for DSM-IV Axis I disorders. New York: Biometrics Research.

Ford JM, Mathalon DH (2004) Electrophysiological evidence of corollary discharge dysfunction in schizophrenia during talking and thinking. J Psychiatr Res 38:37-46. CrossRef Medline

Ford JM, Mathalon DH (2012) Anticipating the future: automatic prediction failures in schizophrenia. Int J Psychophysiol 83:232-239. CrossRef Medline

Ford JM, Mathalon DH, Heinks T, Kalba S, Faustman WO, Roth WT (2001a) Neurophysiological evidence of corollary discharge dysfunction in schizophrenia. Am J Psychiat 158:2069-2071. CrossRef Medline

Ford JM, Mathalon DH, Kalba S, Whitfield S, Faustman WO, Roth WT (2001b) Cortical responsiveness during inner speech in schizophrenia: an event-related potential study. Am J Psychiat 158:1914-1916. CrossRef Medline

Ford JM, Mathalon DH, Kalba S, Whitfield S, Faustman WO, Roth WT (2001c) Cortical responsiveness during talking and listening in schizophrenia: an event-related brain potential study. Biol Psychiatry 50:540549. CrossRef Medline

Ford JM, Gray M, Whitfield SL, Turken AU, Glover G, Faustman WO, Mathalon DH (2004) Acquiring and inhibiting prepotent responses in schizophrenia: event-related brain potentials and functional magnetic resonance imaging. Arch Gen Psychiatry 61:119-129. CrossRef Medline

Ford JM, Dierks T, Fisher DJ, Herrmann CS, Hubl D, Kindler J, Koenig T, Mathalon DH, Spencer KM, Strik W, van Lutterveld R (2012) Neurophysiological studies of auditory verbal hallucinations. Schizophr Bull 38:715-723. CrossRef Medline

Frith C (1992) The cognitive neuropsychology of schizophrenia. Hove, UK: Lawrence Erlbaum.

Frith CD (1987) The positive and negative symptoms of schizophrenia reflect impairments in the perception and initiation of action. Psychol Med 17:631-648. CrossRef Medline

Frith CD, Done DJ (1989) Experiences of alien control in schizophrenia reflect a disorder in the central monitoring of action. Psychol Med 19: 359-363. CrossRef Medline

Gaymard B, Pierrot-Deseilligny C, Rivaud S (1994) Impairment of extraretinal eye position signals after central thalamic lesions. Exp Brain Res 102:1-9. Medline
Guillery RW, Sherman SM (2002) The thalamus as a monitor of motor outputs. Philos Trans R Soc Lond B Biol Sci 357:1809-1821. CrossRef Medline

Gur RE (1978) Left hemisphere dysfunction and left hemisphere overactivation in schizophrenia. J Abnorm Psychol 87:226-238. CrossRef Medline

Hall NJ, Colby CL (2011) Remapping for visual stability. Philos Trans R Soc Lond B Biol Sci 366:528-539. CrossRef Medline

Hallett PE, Lightstone AD (1976) Saccadic eye movements to flashed targets. Vision Res 16:107-114. CrossRef Medline

Heide W, Blankenburg M, Zimmermann E, Kömpf D (1995) Cortical control of double-step saccades: implications for spatial orientation. Ann Neurol 38:739-748. CrossRef Medline

Joiner WM, FitzGibbon EJ, Wurtz RH (2010) Amplitudes and directions of individual saccades can be adjusted by corollary discharge. J Vis 10(2):22 1-12. CrossRef Medline

Kopp B, Rist F (1994) Error-correcting behavior in schizophrenic patients. Schizophr Res 13:11-22. CrossRef Medline

Kopp B, Rist F (1999) An event-related brain potential substrate of disturbed response monitoring in paranoid schizophrenic patients. J Abnorm Psychol 108:337-346. CrossRef Medline

Lindner A, Thier P, Kircher TT, Haarmeier T, Leube DT (2005) Disorders of agency in schizophrenia correlate with an inability to compensate for the sensory consequences of actions. Curr Biol 15:1119-1124. CrossRef Medline

Malenka RC, Angel RW, Hampton B, Berger PA (1982) Impaired central error-correcting behavior in schizophrenia. Arch Gen Psychiatry 39:101107. CrossRef Medline

Malenka RC, Angel RW, Thiemann S, Weitz CJ, Berger PA (1986) Central error-correcting behavior in schizophrenia and depression. Biol Psychiatry 21:263-273. CrossRef Medline

McDowell JE, Clementz BA (1997) The effect of fixation condition manipulations on antisaccade performance in schizophrenia: studies of diagnostic specificity. Exp Brain Res 115:333-344. CrossRef Medline

Minken AW, Van Opstal AJ, Van Gisbergen JA (1993) Three-dimensional analysis of strongly curved saccades elicited by double-step stimuli. Exp Brain Res 93:521-533. CrossRef Medline

Morris SE, Yee CM, Nuechterlein KH (2006) Electrophysiological analysis of error monitoring in schizophrenia. J Abnorm Psychol 115:239-250. CrossRef Medline

Murthy A, Ray S, Shorter SM, Priddy EG, Schall JD, Thompson KG (2007) Frontal eye field contributions to rapid corrective saccades. J Neurophysiol 97:1457-1469. CrossRef Medline

Murthy A, Ray S, Shorter SM, Schall JD, Thompson KG (2009) Neural control of visual search by frontal eye field: effects of unexpected target displacement on visual selection and saccade preparation. J Neurophysiol 101:2485-2506. CrossRef Medline

Oldfield RC (1971) The assessment and analysis of handedness: the Edinburgh inventory. Neuropsychologia 9:97-113. CrossRef Medline

Ostendorf F, Liebermann D, Ploner CJ (2010) Human thalamus contributes to perceptual stability across eye movements. Proc Natl Acad Sci U S A 107:1229-1234. CrossRef Medline

Overall JE, Gorham DR (1962) The brief psychiatric rating scale. Psychol Rep 10:799-812. CrossRef

Park J, Schlag-Rey M, Schlag J (2003) Spatial localization precedes temporal determination in visual perception. Vision Res 43:1667-1674. CrossRef Medline

Park S (1999) Hemispheric asymmetry of spatial working memory deficit in schizophrenia. Int J Psychophysiol 34:313-322. CrossRef Medline

Park S, Holzman PS (1992) Schizophrenics show spatial working memory deficits. Arch Gen Psychiatry 49:975-982. CrossRef Medline

Park S, Nasrallah HA (2014) The varieties of anomalous self experiences in schizophrenia: splitting of the mind at a crossroad. Schizophr Res 152: 1-4. CrossRef Medline

Pisella L, Alahyane N, Blangero A, Thery F, Blanc S, Pelisson D (2011) Right-hemisphere dominance for visual remapping in humans. Philos Trans R Soc Lond B Biol Sci 366:572-585. CrossRef Medline

Polli FE, Barton JJ, Vangel M, Goff DC, Iguchi L, Manoach DS (2006) Schizophrenia patients show intact immediate error-related performance adjustments on an antisaccade task. Schizophr Res 82:191-201. CrossRef Medline

Polli FE, Barton JJ, Thakkar KN, Greve DN, Goff DC, Rauch SL, Manoach DS 
(2008) Reduced error-related activation in two anterior cingulate circuits is related to impaired performance in schizophrenia. Brain 131:971986. CrossRef Medline

Posner MI, Early TS, Reiman E, Pardo PJ, Dhawan M (1988) Asymmetries in hemispheric control of attention in schizophrenia. Arch Gen Psychiatry 45:814-821. CrossRef Medline

Rabbitt PM (1966) Error correction time without external error signals. Nature 212:438. CrossRef Medline

Ray S, Schall JD, Murthy A (2004) Programming of double-step saccade sequences: modulation by cognitive control. Vision Res 44:2707-2718. CrossRef Medline

Reuter B, Herzog E, Kathmann N (2006) Antisaccade performance of schizophrenia patients: evidence of reduced task-set activation and impaired error detection. J Psychiatr Res 40:122-130. CrossRef Medline

Richard A, Churan J, Whitford V, O’Driscoll GA, Titone D, Pack CC (2014) Perisaccadic perception of visual space in people with schizophrenia. J Neurosci 34:4760-4765. CrossRef Medline

Sass LA, Parnas J (2003) Schizophrenia, consciousness, and the self. Schizophr Bull 29:427-444. CrossRef Medline

Schneider K (1959) Clinical psychopathology. New York: Grune and Stratton.

Sharika KM, Ramakrishnan A, Murthy A (2008) Control of predictive error correction during a saccadic double-step task. J Neurophysiol 100:27572770. CrossRef Medline

Shinn AK, Baker JT, Cohen BM, Ongür D (2013) Functional connectivity of left Heschl's gyrus in vulnerability to auditory hallucinations in schizophrenia. Schizophr Res 143:260-268. CrossRef Medline

Sim K, Yang GL, Loh D, Poon LY, Sitoh YY, Verma S, Keefe R, Collinson S, Chong SA, Heckers S, Nowinski W, Pantelis C (2009) White matter abnormalities and neurocognitive deficits associated with the passivity phenomenon in schizophrenia: a diffusion tensor imaging study. Psychiatry Res 172:121-127. CrossRef Medline

Sommer MA, Wurtz RH (2002) A pathway in primate brain for internal monitoring of movements. Science 296:1480-1482. CrossRef Medline

Sommer MA, Wurtz RH (2004) What the brain stem tells the frontal cortex: II. Role of the SC-MD-FEF pathway in corollary discharge. J Neurophysiol 91:1403-1423. CrossRef Medline

Sommer MA, Wurtz RH (2008) Brain circuits for the internal monitoring of movements. Annu Rev Neurosci 31:317-338. CrossRef Medline

Spence SA, Brooks DJ, Hirsch SR, Liddle PF, Meehan J, Grasby PM (1997) A PET study of voluntary movement in schizophrenic patients experiencing passivity phenomena (delusions of alien control). Brain 120:1997-2011. CrossRef Medline

Spering M, Dias EC, Sanchez JL, Schütz AC, Javitt DC (2013) Efference copy failure during smooth pursuit eye movements in schizophrenia. J Neurosci 33:11779-11787. CrossRef Medline

Stephan KE, Baldeweg T, Friston KJ (2006) Synaptic plasticity and dysconnection in schizophrenia. Biol Psychiatry 59:929-939. CrossRef Medline

Thaker GK, Ross DE, Buchanan RW, Moran MJ, Lahti A, Kim C, Medoff D (1996) Does pursuit abnormality in schizophrenia represent a deficit in the predictive mechanism? Psychiatry Res 59:221-237. CrossRef Medline

Thakkar KN, Nichols HS, McIntosh LG, Park S (2011) Disturbances in body ownership in schizophrenia: evidence from the rubber hand illusion and case study of a spontaneous out-of-body experience. PLoS One 6:e27089. CrossRef Medline

Thakkar KN, Schall JD, Logan GD, Park S (2015) Response inhibition and response monitoring in a saccadic double-step task in schizophrenia. Brain Cogn 95:90-98. CrossRef Medline

Turken AU, Vuilleumier P, Mathalon DH, Swick D, Ford JM (2003) Are impairments of action monitoring and executive control true dissociative dysfunctions in patients with schizophrenia? Am J Psychiatry 160:18811883. CrossRef Medline

Van der Stigchel S, Nijboer TCW (2011) The global effect: what determines where the eyes land? J Eye Mov Res 4:1-13.

Van der Stigchel S, Meeter M, Theeuwes J (2006) Eye movement trajectories and what they tell us. Neurosci Biobehav Rev 30:666-679. CrossRef Medline

Waters F, Price G, Dragović M, Jablensky A (2009) Electrophysiological brain activity and antisaccade performance in schizophrenia patients with first-rank (passivity) symptoms. Psychiatry Res 170:140-149. CrossRef Medline

White JM, Sparks DL, Stanford TR (1994) Saccades to remembered target locations: an analysis of systematic and variable errors. Vision Res 34:79-92. CrossRef Medline

Wolpert DM, Ghahramani Z (2000) Computational principles of movement neuroscience. Nat Neurosci 3:1212-1217. CrossRef Medline

Woods SW (2003) Chlorpromazine equivalent doses for the newer atypical antipsychotics. J Clin Psychiatry 64:663-667. Medline

Woodward ND, Karbasforoushan H, Heckers S (2012) Thalamocortical dysconnectivity in schizophrenia. Am J Psychiat 169:1092-1099. CrossRef Medline

Wurtz RH (2008) Neuronal mechanisms of visual stability. Vision Res 48 : 2070-2089. CrossRef Medline 